\title{
Corrigendum: Keeping Track of Greenhouse Gas Emission Reduction Progress and Targets in 167 Cities Worldwide
}

\author{
Ting Wei ${ }^{1+}$, Junliang $\mathrm{Wu}^{1 \dagger}$ and Shaoqing Chen ${ }^{1,2 *}$ \\ ${ }^{1}$ School of Environmental Science and Engineering, Sun Yat-sen University, Guangzhou, China, ${ }^{2}$ Guangdong Provincial Key \\ Laboratory of Environmental Pollution Control and Remediation Technology, Guangzhou, China
}

Keywords: climate change, GHG emission reduction, energy consumption, climate targets, low-carbon cities

\section{A Corrigendum on}

Keeping Track of Greenhouse Gas Emission Reduction Progress and Targets in 167 Cities Worldwide

by Wei, T., Wu, J., and Chen, S. (2021). Front. Sustain. Cities 3:696381. doi: 10.3389/frsc.2021.696381

The authors regret the typing errors in the following sections. Corrections are presented:

\section{OPEN ACCESS}

Approved by:

Frontiers Editorial Office,

Frontiers Media SA, Switzerland

*Correspondence:

Shaoqing Chen

chenshaoqing@mail.sysu.edu.cn

†These authors have contributed equally to this work

Specialty section

This article was submitted to

Urban Energy End-Use,

a section of the journal

Frontiers in Sustainable Cities

Received: 12 October 2021

Accepted: 15 October 2021

Published: 02 November 2021

Citation:

Wei T, Wu J and Chen S (2021)

Corrigendum: Keeping Track of Greenhouse Gas Emission Reduction

Progress and Targets in 167 Cities

Worldwide.

Front. Sustain. Cities 3:793575.

doi: 10.3389/frsc.2021.793575

\section{RESULTS}

\section{GHG Emissions From Cities and Their Sectors}

(1) On page 3, in the $1^{\text {st }}$ paragraph of section "GHG Emissions From Cities and Their Sectors", "Asia countries [such as China (Handan, Shanghai, and Suzhou) and Japan (Tokyo)] and EU countries [such as Russia (Moscow) and Turkey (Istanbul)]" should be replaced by "Asian and European countries [such as China (Handan, Shanghai, and Suzhou) and Japan (Tokyo), Russia (Moscow) and Turkey (Istanbul)]."

(2) On page 3, "109 cities in total" and "Nearly half of the 109 cities" in $3^{\text {rd }}$ paragraph of the section "GHG Emissions From Cities and Their Sectors" should be replaced by "108 cities in total" and "Nearly half of the 108 cities," respectively.

\section{APPENDIX A}

(3) On page 13, Table A1, the "Austria" in the column "continent" should be replaced by "Oceania" for 3 cities (Melbourne, Sydney, and Auckland).

The authors apologize for this error and state that this does not change the scientific conclusions of the article in any way. The original article has been updated.

Publisher's Note: All claims expressed in this article are solely those of the authors and do not necessarily represent those of their affiliated organizations, or those of the publisher, the editors and the reviewers. Any product that may be evaluated in this article, or claim that may be made by its manufacturer, is not guaranteed or endorsed by the publisher.

Copyright (C) 2021 Wei, Wu and Chen. This is an open-access article distributed under the terms of the Creative Commons Attribution License (CC BY). The use, distribution or reproduction in other forums is permitted, provided the original author(s) and the copyright owner(s) are credited and that the original publication in this journal is cited, in accordance with accepted academic practice. No use, distribution or reproduction is permitted which does not comply with these terms. 